\title{
Automatic Detection of Potential Buried Archaeological Sites in Saruq Al-Hadid, United Arab Emirates
}

\author{
Marwa Chendeb EL RAI ${ }^{\mathrm{a}}$, Mina Al-Saad ${ }^{\mathrm{a}}$, Nour Aburaed ${ }^{\mathrm{a}}$, Saeed Al Mansoori ${ }^{\mathrm{b}}$, Hussain \\ Al-Ahmad ${ }^{\mathrm{a}}$, and Stephen Marshall ${ }^{\mathrm{c}}$ \\ ${ }^{a}$ University of Dubai, Dubai, United Arab Emirates \\ ${ }^{b}$ Mohammed Bin Rashid Space Centre, Dubai, United Arab Emirates \\ 'University of Strathclyde, Glasgow, Scotland
}

\begin{abstract}
The use of remote sensing in archaeological research allows the prospection of sub-surfaces in arid regions nonintrusively before the on-site investigation and excavation. While the actual detection method of expected buried archaeological structures is based on visual interpretation, this work provides a supporting archaeological guidance using remote sensing. The aim is to detect potential archaeological remains underneath the sand. This paper focuses on Saruq Al-Hadid surroundings, which is an archaeologist site discovered in 2002, located about $50 \mathrm{~km}$ south-east of Dubai, as archaeologists believe that other archaeological sites are potentially buried in the surroundings. The input data is derived from a combination of wavelength L-band Synthetic Aperture Radar (ALOS PALSAR), which is able to penetrate the sand, and multispectral optical images (Landsat 7). This paper develops a new strategy to help in the detection of suspected buried structures. The data fusion of surface roughness and spectral indices enables tackling the well-known limitation of SAR images and offers a set of pixels having an archaeological signature different from the manmade structures. The potential buried sites are then classified by performing a pixel-level unsupervised classification algorithm such as K-means cluster analysis. To test the performance of the proposed method, the results are compared with those obtained by visual interpretation.
\end{abstract}

Keywords: Multispectral images, SAR images, Landsat, ALOS PALSAR, Archaeology, Fusion, Classification

\section{INTRODUCTION}

Remote sensing plays a vital role in discovering potential buried archaeological sites within a short amount of time, and without excavating the surface and harming evidences or artifacts in the process.

These are two main advantages that remote sensing provides as opposed to other traditional methods. Nowadays, Geographical Information System (GIS) analysis is considered essential in archaeology research, which utilizes spatial characterisation of archaeological sites based on geomorphological parameters. The availability of high-resolution remote sensing images facilitates the possibility of extracting spatial characteristics. One example of such technology is utilizing microwave sensors to capture Synthetic Aperture Radar (SAR) images, which are known for identifying underground objects. SAR images have been widely used to study various archaeological sites around the world since the 1980s. ${ }^{1}$ However, these early applications suffered from several limitations that include the lack of publicly available data and the complexity of data processing. Currently, the wide availability of SAR images and different commercial image processing tools such as ( ENVI, ArcGIS, and SNAP) make the processing of SAR images easier and more affordable. ${ }^{2}$ Depending on the climate and the nature of soil, different spectral indices were considered useful in identification of the buried archaeological structures. In the study done by, ${ }^{3}$ the Normalized difference vegetation index (NDVI) and edge detection method that were obtained using QuickBird satellite images had been used to investigate the surface crop marks to identify any subtle change showing the presence of buried archaeological structures in Italy. ${ }^{3}$ Our work focuses on Saruq Al-Hadid (SA) archaeological site located in the desert. SA has been discovered in 2002 and since that time, many excavation

Further author information: (Send correspondence to Marwa Chendeb EL RAI)

Marwa Chendeb EL RAI.: E-mail: mcelrai@ud.ac.ae, Telephone: +971 45566800 
have been performed to find more than 15000 artefacts featuring the rich immersive and interactive story of Saruq al-Hadid that dates back to the Iron Age 4-7. The archaeologists believe that other archaeological sites are potentially buried in the surroundings of SA. In the case of arid regions, the input data is derived from a combination of wavelength L-band Synthetic Aperture Radar (ALOS PALSAR) which is able to penetrate the sand, and multispectral optical images (Landsat 7). This work is the first attempt made until now in evaluating the detectability of archaeological remains using satellite Synthetic Aperture Radar (SAR) data and multispectral data in United Arab Emirates. The use of remote sensing satellite radar images enhances widely the possibilities of archaeological prospection. This project aims to prescreen potential buried archaeological sites in the desert region. The proposed method helps in mapping automatically the expected buried structures to guide the archaeologists for the planning of future excavation campaigns. Remote sensing fusion have been performed at three levels: pixel-level, image-level, and feature-level 8. In this study, the fusion of Landsat 7 data and Advanced Land Observing Satellite-1 (ALOS 1) data was conducted by combing the spectral indices calculated form landsat 7 and the backscatterer HH calculated from ALOS image, following by unsupervised classification to determine the clusters that meet the requirements for potential buried structures. The rest of this paper is structured as follows. Section 2 describes the study area. Section 3 demonstrates the proposed method. The validation of results and applicability of our approach are elaborated in Section 4. Sections 5 reports the discussions and conclusions.

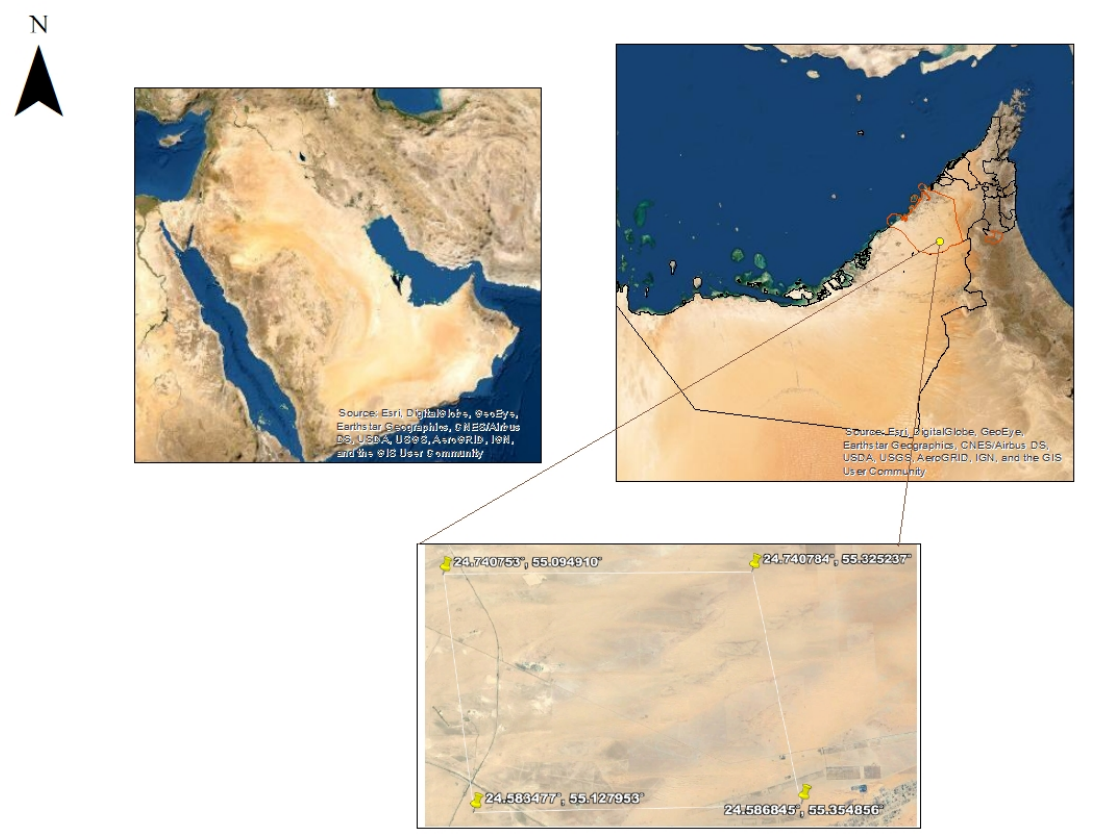

Figure 1. Study Area of Saruq al-Hadid, United Arab Emirates.

\section{STUDY AREA}

Saruq Al-hadid (SA), "the Way of Iron", an archaeological site that is considered of international significance that offers the keys to discover the industrial activity, trade, and everyday life in Iron Age in the Arabian Peninsula. It is Located at $50 \mathrm{~km}$ in the southeast of Dubai at the north of al Rub'al khali desert, in United Arab Emirates (UAE). The four corner geographic coordinates for the study area are $24.740753^{\circ} 55.094910^{\circ}$, $24.583477^{\circ} 55.127953^{\circ}, 24.586845^{\circ} 55.354856^{\circ}$, and $24.740784^{\circ} 55.325237^{\circ}$ as shown in Fig. ??. Archaeological prospection in Saruq al hadid gains significant interest in aim to find the complete story of prehistoric settlements in that area. The location of this site which was a centre for metalworking three thousand years ago, in the middle of the desert between the dunes is weird as there is no available close freshwater critical for human survival and raw material sources critical for metallurgical industry 6,7 . 
Table 1. Landsat 7 Spectral Bands.

\begin{tabular}{|c|c|c|}
\hline Band & Wavelength $(\mu \mathrm{m})$ & Resolution (meter) \\
\hline Band1 (Visible) & $0.45-0.52$ & 30 \\
\hline Band2 (Visible) & $0.52-0.60$ & 30 \\
\hline Band3 (Visible) & $0.63-0.69$ & 30 \\
\hline Band4 (Near-Infrared) & $0.77-0.90$ & 30 \\
\hline Band5 (Near-Infrared) & $1.55-1.75$ & 30 \\
\hline Band6 (Thermal) & $10.40-12.50$ & $60(30)$ \\
\hline Band7 (Mid-Infrared) & $2.09-2.35$ & 30 \\
\hline Band8 (Panchromatic (PAN) ) & $0.52-0.90$ & 15 \\
\hline
\end{tabular}

Table 2. Dataset Acquisition Date

\begin{tabular}{cc}
\hline \hline Satellite & Acquisition Date \\
\hline Landsat 7/ ETM+ & 26 January 2011 \\
ALOS/PALSAR & 15 January 2011 \\
\hline
\end{tabular}

\section{MATERIALS AND METHODS}

\subsection{Data used}

Both optical and Synthetic Aperture Radar (SAR) images, Landsat 7 Enhanced Thematic Mapper Plus (ETM+) and ALOS PALSAR were used in this study. Landsat 7 images have seven spectral bands (Band1-Band7) with a spatial resolution of 30-meter as shown in Tab. 1 . Advanced Land Observing Satellite-1 (ALOS-1) PALSAR (Phased Array type L-band Synthetic Aperture Radar) imagery with a spatial resolution of $6.25 \mathrm{~m}$ and single mode polarization $(\mathrm{HH})$ was also used in this research. The acquisition date for all the images was on January 2011 as given in Tab. 2.

\subsection{Pre-processing}

After downloading ALOS PALSAR scene, radiometric calibration and speckle filtering with Lee Sigma filer 5x5 window size have been performed. A digital elevation model of Shuttle Radar Topography Mission (SRTM) with a spatial resolution of $30 \mathrm{~m}$ is applied for Range Doppler terrain correction. Landsat 7 is reprojected into the World Geodetic System WGS84 latitude/longitude Grid.

\subsection{Method}

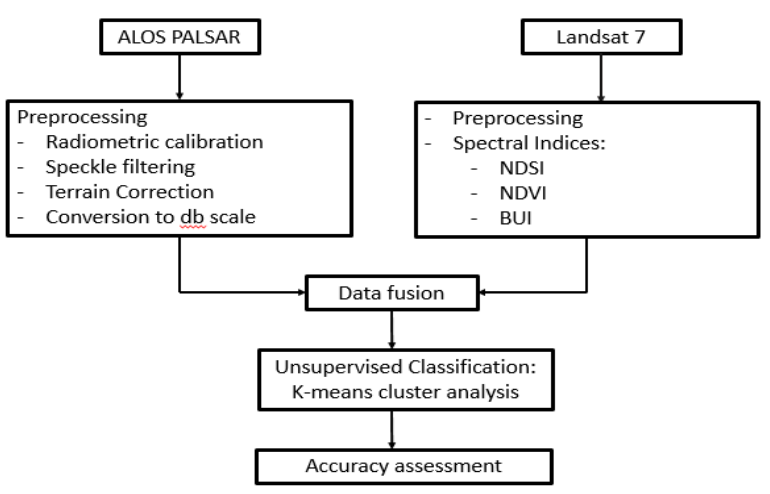

Figure 2. Framework of our proposed method which takes into account the input from SAR and multispectral images. 
At pixel level, fusion methods merge data of various sensors to exploit the complementary data content 8 . In the case of archaeological screening in arid environment, the main concern is to find bare or sandy regions that shows backscatterers in SAR images. The backscattered values of $\mathrm{HH}$ polarization is included as valuable important information in the identification of expected buried structures.

\section{Normalized Difference Sand Index}

For Landsat 7, seven solar reflectance bands (Bands 1-7) from $0.45-2.35 \mu \mathrm{m}$ are identified. The difference between the band 3 with high reflectance and band 1 with low reflectance, reveals the sand characteristics and distinguishes well between the sand and other soil features 9. Based on this strong discriminability, NDSI is used as an input for the classification process. NDSI is written as follows Equation (1):

$$
N D S I=\frac{\left(\rho_{\text {Red }}-\rho_{\text {Blue }}\right)}{\left(\rho_{\text {Red }}+\rho_{\text {Blue }}\right)},
$$

where $\rho_{\text {Red }}$ and $\rho_{\text {Blue }}$ are the reflectances of the blue and red bands respectively. The sand dominates the region where NDSI has higher values. The defined sand index can discern better the sand from other soil, and it is more appropriate for the images of Landsat 710.

\section{Normalized Difference Vegetation Index}

In the desert, the shrubs are reflected in SAR images in single and double bounce 11. The NDVI input for the classification algorithm is an important index to remove the shrub areas. Shrub NDVI values from 0 to 0.21 were classified as desert shrub 12. In the archaeological prospection, the bright regions related to shrubs are excluded by eliminated the clusters where NDVI is greater than 0 . The Normalized Difference Vegetation Index is written as Equation (2):

$$
N D V I=\frac{\left(\rho_{N I R}-\rho_{R e d}\right)}{\left(\rho_{N I R}+\rho_{R e d}\right)},
$$

where $\rho_{N I R}=$ band4 and $\rho_{\text {Red }}=$ band 3 in Landsat 7 .

\section{Built-Up Index}

Spectral disparity of built-up area is low in the Blue band; however, it is large in the SWIR2 band. The distinction between sandy soils and buildings is better shown in Blue and SWIR2 bands in the arid climate 13. The proposed build up index in dry climate is expressed as Equation (3):

$$
B U I=\frac{\left(\rho_{\text {blue }}-\rho_{\text {SWIR2 }}\right)}{\left(\rho_{\text {blue }}+\rho_{\text {SWIR2 }}\right)},
$$

where $\rho_{b l u e}=$ band 1 and $\rho_{S W I R 2}=$ band 7 .

NDSI, NDVI and BUI were calculated using the pan-sharpened Landsat-7 bands. Then, the spectral indices and backcatterer HH were merged and resampled into the geographical raster of the ALOS PALSAR which has the highest spatial resolution of $6.25 \mathrm{~m}$ using bilinear interpolation. The obtained stack image is composed of:

- ALOS PALSAR: HH

- Landsat-7 indices: NDSI, NDVI and BUI.

The spectral indices values and backscatterers served as input to the classification algorithm. The workflow of the proposed approach is shown in Fig. 2. To create clusters that are associated to the expected buried structures, the unsupervised pixel level classification "K-means cluster analysis" was performed. For K-means cluster analysis, the initial class means of distributed data are calculated, then the pixels are clustered into the nearest class after computing the minimum distance between the means and the pixels to classify. At each iteration, the class means are recalculated and the pixels are reclassified. In our case, the process ends when the maximum number of iteration is reached. The number of iterations is set to be 30 . 

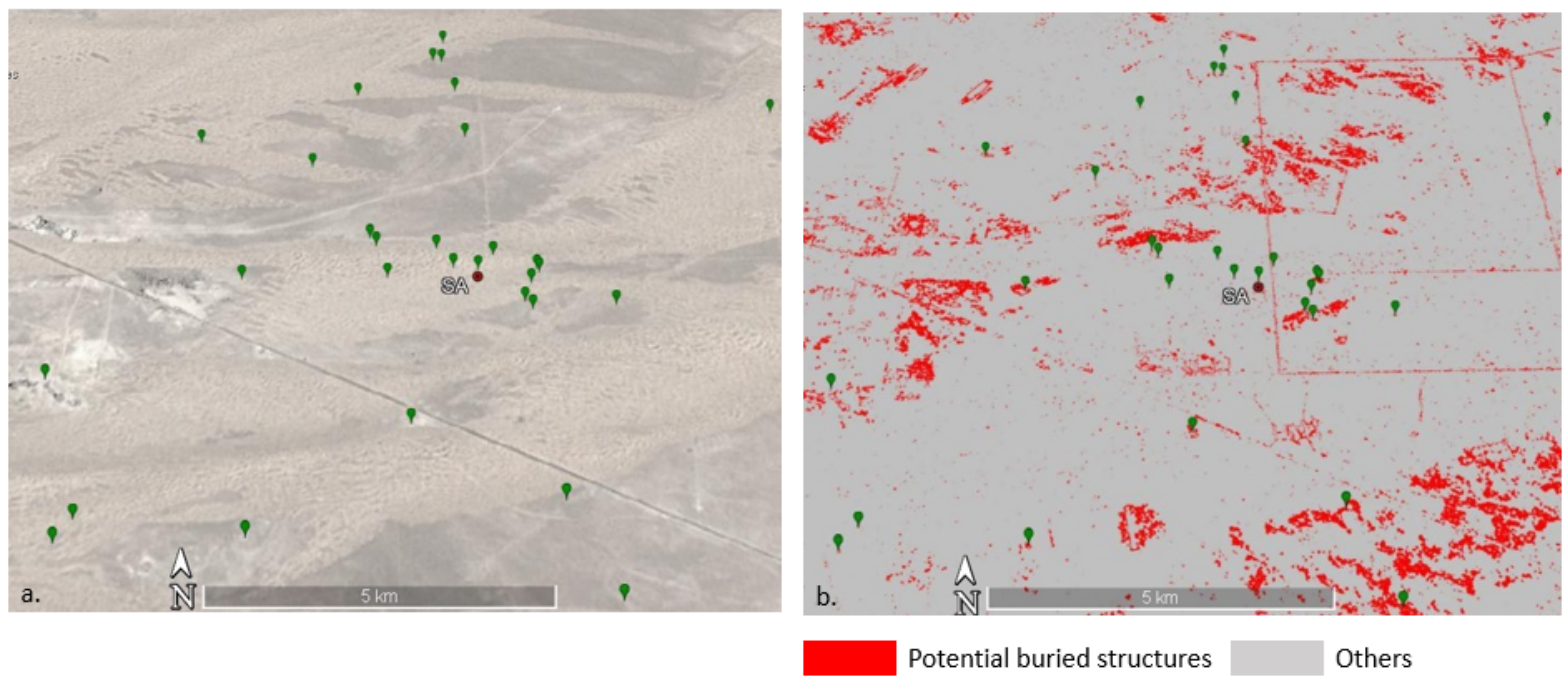

Figure 3. a. Google earth image where the green landmarks are the expected buried sites identified by visual interpretation. b. Mapping the expected archaeological using our proposed approach.

\section{RESULTS}

In order to evaluate the distinctiveness of the hidden structures in the desert in terms of optical and SAR values, the classified multispectral and SAR signatures were compared to the potential sites that have been identified by visual interpretation distributed within the study area as shown in Fig. 3. The green landmarks shown in Fig. 3 have been identified by spotting visually the regions of SAR images which show brightness although the optical image is sand or bare soil at the same location. The fused data composed of the three composite bands NDSI, NDVI and BUI and SAR image provided satisfactory results. The total number of potential sites detected by visual interpretation in the study area are 45 sites (30 sites are shown in Fig. 3). 40 sites have been classified in the cluster of hidden structures. Although the accurate results (90\%), the rate of false positive is high too but it helps to explore missing regions that could be candidate for expected archaeological sites missed by visual interpretation. However, the approach is a very important tool to help the researchers to focus in some regions instead to study all the SAR scene and compare each bright point with the optical image. From the visual aspect, the findings show that the approach proposed is suitable to the complementary imaging mechanism between SAR and multispectral images.

\section{DISCUSSION AND CONCLUSIONS}

The aim of this study is to explore the fusion and the relationship between the multispectral and SAR images in arid environment. The classification method is applied to identify one class associated to regions reflecting backscatterers in bare or sandy soil. Then our approach is compared with the results obtained by visual interpretation, which shows accurate results, $90 \%$ of sites are detected. The freely available images led to the use of Landsat 7 and ALOS PALSAR images acquired in 2011. In further studies, it is necessary to apply the proposed method to images acquired by other sensors. Second, further verification is needed when considering other SAR and multispectral images with higher spatial resolution to explore more hidden structures. A yearly study of SAR and multispectral images with high temporal correlation is needed for further screening of potential hidden archaeological sites.

\section{ACKNOWLEDGMENTS}

This research was supported and funded by Mohammed bin Rashid Space Center (MBRSC). The data were provided by European Space center and Earth data Alaska supported by NASA. 


\section{REFERENCES}

[1] P. Merola, A. Allegrini, D. G. and Sampieri, S., "Buried archaeological structures detection using mivis hyperspectral airborne data," Proceedings of SPIE - Infrared Spaceborne Remote Sensing XIV 6297 (2006).

[2] S. Sharafi, S. Fouladvand, I. S. and Alvarez, J., "Application of pattern recognition in detection of buried archaeological sites based on analysing environmental variables, khorramabad plain, west iran," Journal of Archaeological Science: Reports 8, 206-215 (2016).

[3] Lasaponara, R. and Masini, N., "Identification of archaeological buried remains based on thenormalized difference vegetation index (ndvi) from quickbird satellite data," Proc. SPIE- IEEE International Geo science and Remote Sensing Letters 3, 325-328 (2009).

[4] L. weeks, Ch. Cable, K. F. and al., "Recent archaeological research at saruq al-hadid, dubai, uae," Arabian archaeology and epigraphy, 31-60 (2017).

[5] Contreras, F. and al., "Excavations in area 2a at saruq al-hadid: Iron age ii evidence of copper production and ceremonial activities," Proceedings of the Seminar for Arabian Studies, 57-66 (2017).

[6] J.T. Herrmann, J. C. and Qandil, H., "Settlement history in the eastern rub al-khali: Preliminary report of the dubai desert survey (2006-2007)," AAE 20, 30-45 (2009).

[7] I. Stepanov, L. Weeks, B. O. P. M. O. A. and al., "The provenance of early iron age ferrous remains from southeastern arabi," Journal of Archaeological Science. 120 (2020).

[8] Ghassemian, H., "A review of remote sensing image fusion methods," Elsivier, Information Fusion 32, 75-89 (2016).

[9] X. Pan, X. Zhu, Y. Y. C. C. X. Z. and Shan, L., "Applicability of downscaling land surface temperature by using normalized difference sand index.," Nature Scientific Reports 8 (2018).

[10] Fadhil, A. M., "Sand dunes monitoring using remote sensing and gis techniques for some sites in iraq," Intelligent Information, Control, and Communication Technology for Agricultural Engineering. International Society for Optics and Photonics. (2013).

[11] L. White, B. Brisco, M. D. A. S. and Pratt, A., "A collection of sar methodologies for monitoring wetlands," Remote Sensing 7, 7615-7645 (2015).

[12] E. Youhao, W. Jihe, G. S. Y. P. and Zihui, Y., "Monitoring of vegetation changes using multi-temporal ndvi in peripheral regions around minqin oasis, northwest china," IEEE International Geoscience and Remote Sensing Symposium, 3448-3451 (2007).

[13] A. Rasul, H. B. and al., "Applying built-up and bare-soil indices from landsat 8 to cities in dry climates.," Land 7 (2018). 